\title{
Dynamics of nasal eosinophils in response to a nonnatural allergen challenge in patients with allergic rhinitis and control subjects: A biopsy and brush study
}

\author{
Tom Godthelp, MD, a, b Adriaan F. Holm, MD, \\ Wytske J. Fokkens, MD, PhD, ${ }^{b}$ Peter Doornenbal,a \\ Paul G. H. Mulder, MSc, ${ }^{c}$ Elisabeth C. M. Hoefsmit, MD, PhD, ${ }^{d}$ \\ Alex Kleinjan, ${ }^{a}$ E. P. Prens, MD, PhD, a and Evert Rijntjes, MD, PhDe \\ Rotterdam, Amsterdam, and The Hague, The Netherlands
}

\begin{abstract}
Background: Eosinophils are thought to play an important role in the symptomatology and pathophysiology of allergic rhinitis. Most quantitative studies on eosinophils in nasal mucosa have focused on the dynamics of eosinophils in the acute and late phases of the allergic reaction by using different cell sampling techniques. Little is known about the dynamics of eosinophils during a more prolonged period of allergen exposure and the activation of eosinophils induced by allergen challenge.

Objective: The aim of this study was to investigate the dynamics and activation of the eosinophils in the nasal mucosa of patients with an isolated grass pollen allergy during an out-of-season 2-week allergen exposure, mimicking the natural grass pollen season.

Methods: Seventeen patients with isolated grass pollen allergy and four control subjects were challenged daily with the allergen during a 2-week period in the winter. Nasal brush specimens were obtained before provocation and each day during the provocation period. Biopsy specimens were obtained once before, six times during, and once after the provocation period. Preparations made of nasal brush and nasal biopsy specimens were stained with the monoclonal antibody BMK 13 and Giemsa stain as paneosinophil markers and with the monoclonal antibody EG2 to identify activated eosinophils.

Results: We found significant increases in the total number of eosinophils and the number of activated eosinophils in the epithelium and lamina propria. These increases were most explicit in the second week. BMK 13 was found to be a paneosinophil marker superior to Giemsa staining.

Conclusion: Eosinophils are not only involved in the acute and late phases of the allergic reaction but are probably even more involved in the chronic phase. (J ALLERGY CLIN IMMUNOL 1996;97:800-11.)
\end{abstract}

Key words: Eosinophils, grass pollen, rhinitis, allergy, nasal biopsy specimens, nasal brush specimens, allergen challenge

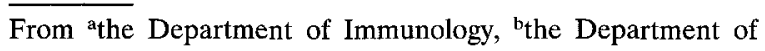
Otorhinolaryngology, and cthe Department of Biostatistics, Erasmus University, Rotterdam; dhe Department of Cell Biology, EM Division, Free University, Amsterdam; and ethe Department of Otorhinolaryngology, Leyenburg Hospital, The Hague, The Netherlands.

Supported by Glaxo and The Duth Astma Foundation.

Received for publication Aug. 23, 1994; revised May 15, 1995; accepted for publication May 22, 1995.

Reprint requests: Tom Godthelp, MD, Department of Immunology, Erasmus University, PO Box 1738, 3000 DR Rotterdam, The Netherlands.
The pathophysiology of the inflammatory reaction in nasal allergy is associated with the presence of a variety of immunologically active cells (e.g., eosinophils, mast cells, $\mathrm{T}$ lymphocytes, $\mathrm{IgE}^{+}$cells, and HLA class II-positive cells). ${ }^{1-3}$ Although our knowledge of nasal allergy has increased substantially during the last few years, much remains to be

Copyright $(0) 1996$ by Mosby-Year Book, Inc. 0091-6749/96 $\$ 5.00+0 \quad \mathbf{1 / 1} / \mathbf{6 6 6 6 9}$ 


\section{Abbreviation used}

PBS: Phosphate-buffered saline

elucidated about the cellular mechanisms and mediators involved.

The eosinophil leukocyte plays an important, though not very clear, role in various allergic disorders. Until now a considerable number of studies that investigated the dynamics of eosinophils in allergic disease during the grass pollen season ${ }^{4}$ and during nonnatural allergen provocation have been performed..$^{5-9}$ The influx of eosinophils has been studied during the immediate reaction $^{5,10}$; during the late phase reaction, which probably represents the naturally occurring allergic disease much more closely than does the acute response ${ }^{11}$; and during repeated allergen challenge..$^{8,9}$ Despite these studies, little is known about the activation of eosinophils.

Different techniques have been used in previous studies to obtain specimens from the nasal mucosa for analysis of mediators and cells. Most of these techniques such as nasal lavage that samples cells floating in the nasal secretion, ${ }^{6,12}$ mucosal imprints, ${ }^{13}$ smear techniques, ${ }^{14}$ and mucosal scrapings ${ }^{15,}{ }^{16}$ represent the mucosal surface and nasal secretions.

Because allergic rhinitis is caused by prolonged or continuous allergen exposure, the aim of this study was to investigate the dynamics and activation of the eosinophils in the epithelium and lamina propria of the nasal mucosa in patients with an isolated grass pollen allergy during an out-ofseason 2-week allergen exposure, mimicking the natural grass pollen season. The advantages of an artificial challenge study are the well controlled conditions, such as allergen dose, and the precise beginning and end of the challenge period. In this way information can be obtained not only about the dynamics of eosinophils in the acute and late phases but also about the continuous allergic reaction. To obtain maximum information we have repeatedly taken nasal biopsy and brush specimens. The biopsy technique allows studies of both epithelial and subepithelial layers ${ }^{5,7,17}$ and is therefore the most suitable for investigating the dynamics of cells in the allergic reaction. Biopsy specimens obtained by a Gerritsma forceps can also be taken several times in a short period without too much discomfort for the patient. ${ }^{17,18}$ An advantage of the brush technique is that repeated harvesting of cells from the nasal mucosa is possible, and it provides better reflection of the cellular events taking place within the actual epithelial lining than nasal lavage. ${ }^{16,19}$ For the staining of the total number of eosinophils, Giemsa solution and a monoclonal antibody (BMK 13) directed to major basic protein of eosinophils ${ }^{20}$ were used. For the determination of activated eosinophils a monoclonal antibody (EG2) directed to eosinophilic cationic protein, which can be detected in activated eosinophils was used. ${ }^{20}$ Electron microscopy was performed to obtain additional information concerning the degranulation aspects of eosinophils.

\section{METHODS \\ Patients and control subjects}

Seventeen patients and four control subjects participated in this study. The patients ( 7 men and 10 women with a mean age of 29 years [range, 14 to 48 years]) had an isolated grass pollen allergy for at least 1 year, which was confirmed by a positive skin prick test reaction to ALK Soluprick extract (ALK, Groningen, The Netherlands) of $1 \mathrm{SQ} / \mathrm{ml}$ and no other positive skin prick test reaction to 13 other common inhalant allergens, a median RAST score of $4+$ (range, $3+$ to $5+$ ), and a median total IgE value of $290 \mathrm{IU} / \mathrm{L}$ (range, 22 to 1900 $\mathrm{IU} / \mathrm{L})$. The four control subjects ( 2 men and 2 women with a mean age of 28 years [range, 24 to 44 years]) had no nasal complaints; no abnormalities in the nose at the time of ear, nose, and throat examination; and negative skin prick test reactions to ALK Soluprick extract of grass pollen and 13 other common inhalant allergens. None of the patients or control subjects used any medication during the study, and none had an infection of the respiratory tract or any nasal complaints during the week preceding the challenge.

None of the patients had any complications during or after the study as a result of repetitive challenge, brushing, or biopsy.

\section{Design of the study}

Patients and control subjects were challenged with allergen daily during a 2-week period. Symptoms and signs were recorded each day. At each visit specimens of epithelial cells were collected from patients and control subjects by the brush technique. Furthermore, during this 2-week period, biopsy specimens were taken from all patients three or four times, and from all control subjects, two times. To allow investigation of a time-related effect, the patients were randomly divided into two groups for statistical reasons, so that a sufficient number of different biopsy moments in time could be analyzed. Thus biopsy specimens were taken from the patients with allergy at seven different moments, as shown in Table I. In both groups one patient underwent biopsy only once, and no brush specimens were obtained from these individuals. One patient in group I underwent 
TABLE I. Biopsy moments

\begin{tabular}{|c|c|c|c|c|}
\hline \multirow[b]{2}{*}{ Patient group } & \multicolumn{3}{|c|}{ Biopsy moment } & \\
\hline & A & B & C & \\
\hline $\mathrm{I}(\mathrm{N}=7)$ & $\begin{array}{l}\text { Before provocation } \\
\quad(n=8)\end{array}$ & $24-48$ hr $(n=5)$ & $8-10$ days $(n=6)$ & \multirow{2}{*}{$\begin{array}{l}1-2 \text { wk after last provocation } \\
\quad(n=9)\end{array}$} \\
\hline II $(\mathrm{N}=10)$ & $\begin{array}{l}1 / 2 \mathrm{hr}(\mathrm{n}=5) \\
8 \mathrm{hr}(\mathrm{n}=5)\end{array}$ & 4-6 days $(\mathrm{n}=9)$ & 14 days $(n=9)$ & \\
\hline
\end{tabular}

For statistical evaluation patients were split in two groups (I and II) before and during provocation.

$N$, Number of patients; $n$, number of biopsies.

biopsy only twice. Brush specimens were obtained in this case. The control subjects were also divided into two groups and underwent biopsy twice. Two control subjects underwent biopsy before provocation and 12 days after the first provocation. The other two control subjects underwent biopsy 24 hours and 12 days after the first provocation. All patients and control subjects gave their informed consent. The study was approved by the medical ethics committees of the Leyenburg Hospital.

\section{Nasal allergen challenge}

Patients and control subjects were challenged daily with a grass pollen extract (ALK Soluprick obtained from Diephuis, Groningen, The Netherlands) with a pump spray delivering a fixed dose of $50 \pm 2 \mu \mathrm{l}$ sprayed in both nostrils. Before provocation, the subjects waited 15 minutes to allow the nasal mucosa to become acclimatized to room temperature. On the first day of the provocation, the patients were challenged with $1000 \mathrm{SQ} / \mathrm{ml}$, followed by increasing doses $(3000,10,000,30,000$, and $100,000 \mathrm{SQ} / \mathrm{ml})$ of allergen to establish a threshold dose. The duration of the interval between two doses was 15 minutes. Within 15 minutes of each challenge, the number of sneezes was counted and the amount of secretion, collected in preweighed paper tissues, was determined. The lowest concentration that produced either more than $0.5 \mathrm{mg}$ of secretion or more than five sneezes in 15 minutes was called the threshold dose. In the following days the same concentration was used until the patient experienced serious complaints (i.e., a score of 3 [severe symptoms] for two or more items of the symptom score of the previous day), at which point a new threshold dose was established.

\section{Symptom scores}

Before each provocation patients were asked which symptoms they had experienced during the previous day. These symptoms (nasal blockage, nasal discharge, sneezing, nasal itching, and eye watering or irritation) were recorded on a 4-point scale ( 0 to 3 ). The total symptom score was calculated as the sum of the individual symptom scores recorded. The symptom score was also used to grade symptoms 30 minutes after each provocation.

\section{Nasal brushes}

A gynobrush (Medeco, Eindhoven, The Netherlands), a small nylon brush used for cell sampling, was intro- duced in the middle meatus of the nose and turned carefully. The brush was immediately placed in a $5 \mathrm{ml}$ polystyrene plastic tube containing $5 \mathrm{ml}$ of phosphate buffered saline (PBS) and was cut off just above the bristles. The tube with the brush was closed and stored at $4^{\circ} \mathrm{C}$ until transport to the laboratory. On arrival in the laboratory, the brush was shaken vigorously in the solution and carefully brushed off against the wall of the tube. The tubes were centrifuged at $400 \mathrm{~g}$ for 10 minutes. After the supernatant was collected, the cells were resuspended in $250 \mu \mathrm{l}$ of PBS. If a higher degree of dispersion was desired, the cell samples were treated with trypsin for 30 minutes at $37^{\circ} \mathrm{C}$. Aliquots of $50 \mu \mathrm{l}$ of the cell suspensions, containing approximately $10^{6}$ cells/ $\mathrm{ml}$, were loaded into a cytocentrifuge (Nordic, Tilburg, The Netherlands) and spun for 5 minutes at $400 \mathrm{~g}$. The cytocentrifuge preparations were checked and consisted mainly of fully dispersed cells; occasionally, small cell clumps ( 5 to 8 cells) were found. If necessary, the cell suspensions were further diluted or concentrated to obtain appropriate cytocentrifuge preparations so that a minimum of 500 cells could be evaluated. If necessary, the specimens were sealed in $\mathrm{N}_{2}$ gas-containing little plastic sacks and stored at $-20^{\circ} \mathrm{C}$ until staining was done.

\section{Nasal biopsy specimens}

Biopsy specimens of nasal mucosa were taken from the lower edge of the inferior turbinate, about $2 \mathrm{~cm}$ posterior to the front edge with Gerritsma forceps with a cup diameter of $2.5 \mathrm{~mm}$. Local anesthesia was achieved by placing a cotton-wool carrier with 50 to $100 \mathrm{mg}$ of cocaine and 3 drops of epinephrine $(1: 1000)$ under the inferior turbinate without touching the area from which the biopsy specimen would be taken. ${ }^{18}$ For light microscopic evaluation, the biopsy specimens were embedded in Tissue-Tek II OCT compound (Miles, Inc. Diagnostics Div., Tarrytown, N.Y.) in a gelatin capsule and frozen immediately. ${ }^{21}$ Biopsy specimens from the patients with allergy were taken at $1 / 2$ hour, 8 hours, and 24 hours after the first provocation and at 2, 4, 6, 8, 10, and 14 days after the first provocation and 1 and 2 weeks after the last provocation (Table I). The biopsy specimens from the control subjects were collected before the first provocation and at 24 hours and 12 days after the 
last provocation. Biopsy specimens were always taken before a new provocation took place. From each specimen, serial sections were cut on a Reichert-Jung 2800 Frigocut cryostat (Leica, Inc., Optical Products Div., Buffalo, N.Y.) and transferred to gelatin-coated microscope slides for light microscopic evaluation. For electon microscopy, biopsy specimens of two patients were immediately immersed in $1.5 \%$ glutaraldehyde in $0.1 \mathrm{~mol} / \mathrm{L}$ sodium cacodylate buffer adjusted to $\mathrm{pH} 7.4$ at $4^{\circ} \mathrm{C}$. After 24 hours, the tissue fragments were washed and postfixed in $1 \% \mathrm{OsO}_{4}$ in the same buffer, dehydrated in ethanol, and embedded in Epon (Merck, Amsterdam, The Netherlands). Semi-thin sections were stained with Giemsa stain. These sections were used for the selection of areas where eosinophils were present. The selected areas were then trimmed for ultramicrotomy, and the ultrathin sections were contrasted with $5 \%$ uranyl acetate and lead citrate according to the method of Reynolds $^{22}$ before examination with a Philips EM 300 electron microscope (Philips Electronic Instruments, Inc., Mahwah, N.J.) at $60 \mathrm{kV}$ with the use of an objective with a $30 \mathrm{~nm}$ aperture.

\section{Staining procedure for biopsy sections and cytocentrifuge preparations}

The brush cytocentrifuge preparations and a part of the biopsy serial sections were fixed with methanol for 3 minutes and stained with Giemsa stain for 20 minutes, washed in tap water, air-dried, and finally mounted in Entallan (Merck \& Co., Inc., Whitehouse Station, N.J.). For immunohistochemistry the alkaline phosphatase method was used. ${ }^{23}$ In brief, $6 \mu \mathrm{m}$ thick sections of nasal mucosa were transferred to gelatin-coated microscope slides, dried, fixed in acetone for 10 minutes at $20^{\circ} \mathrm{C}$, rinsed in PBS ( $\mathrm{pH} 7.2$ ), and incubated with BMK 13 (Genzyme, Cambridge, Mass.), EG2 (Pharmacia, Uppsala, Sweden) monoclonal antibodies and irrelevant control antibodies for 30 minutes at $20^{\circ} \mathrm{C}$. The sections were rinsed again in PBS for 5 minutes and incubated for 15 minutes with a rabbit anti-mouse immunoglobulin antiserum conjugated to alkaline phosphatase (DAKO D3 14; Dakopatts, Copenhagen, Denmark) 1:20, supplemented with $10 \%$ normal human serum to saturate $\mathrm{Fc}$ receptors and reduce background staining; sections were then rinsed successively in PBS and Tris buffer ( $\mathrm{pH}$ 8.0) and incubated for 30 minutes with a New Fuchsin solution (Chroma, Stuttgart, Germany). Finally, the sections were rinsed with distilled water, counterstained with Mayer's hematoxylin, and mounted in glycerin-gelatin. Control sections incubated with irrelevant monoclonal antibodies of the same subclass were negative.

\section{Light and electron microscopic evaluation}

In two sections of each biopsy specimen, all eosinophils with nuclei in the plane section were counted. The number of eosinophils in the epithelium and lamina propria were counted separately. The total surface area of two sections and of the epithelium and lamina propria were determined by computer image analysis (Kontron's Image Analysis System Videoplan; Kontron Instruments, Inc., Everett, Mass.). The number of eosinophils per square millimeter section area in epithelium and lamina propria was calculated. In the Giemsa-stained cytocentrifuge preparations differential counts were performed on 500 cells. For each brush specimen the percentage of eosinophils was calculated. For electron microscopy, the ultrathin sections were evaluated qualitatively only.

\section{Statistical analysis}

For the biopsy part of the study, the 17 patients were split in two groups, each with its own measurement scheme: before and during provocation for statistical reasons (Table I). Three repeated measurements were made for each of the two groups one before (A) and two during the provocation $(B, C)$, together constituting six points on a time axis. Because the variables that were evaluated were symmetrically distributed after log transformation (i.e., with skewness tested to be nonsignificant), a repeated-measures analysis of variance was performed. In this analysis the six time effects on the dependent variable are obtained as the estimates of six coefficients in a saturated model with three withinsubject repetitions for the time effect (two coefficients), two between-subject repetitions for the grouping effect (one coefficient), the interaction between repetition time and group. Relevant are significant differences in time effect and no significance of the grouping and interaction effect (two coefficients) and a constant term (one coefficient). The differences between the end of the provocation period and the period 1 to 2 weeks after the last provocation were analyzed with the sign test. Rank correlation coefficients between symptoms and number of eosinophils per square millimeter in epithelium and lamina propria, between symptoms and percentages of eosinophils in brush specimens, and between number eosinophils per square millimeter in epithelium and lamina propria and percentages of eosinophils in brush specimens were determined.

Concerning the nasal brush specimens, the percentage of eosinophils is considered a quadratic function of time (day 0 to day 15). The coefficients of this function are estimated by means of logistic regression analysis with random effects because of the 16 repeated measurements per patient. A concave function of time was estimated (time effect: $p<0.001$ ), with its maximum at about day 9 .

\section{RESULTS Symptom scores}

During the 2-week daily provocation period, the symptom scores of nasal blockage, nasal discharge, sneezing, nasal itching and the total symptom score recorded on the preceding day increased significantly (Fig. 1). The symptom scores of eye watering or itching did not increase significantly. Also, 


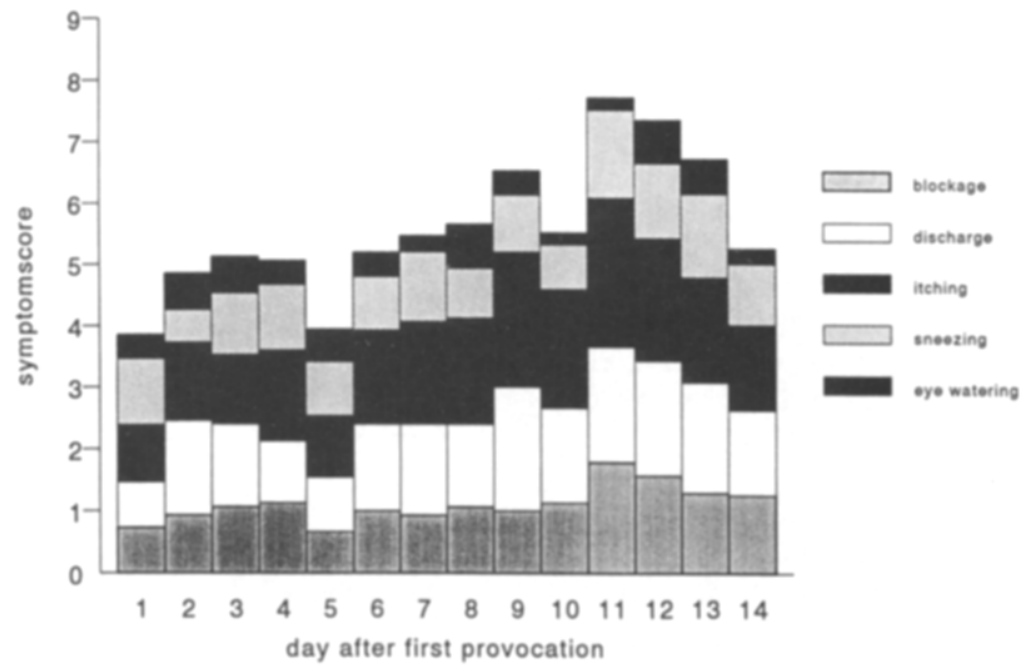

FIG. 1. Mean values of nasal symptoms: blockage, discharge, sneezing, itching, and eye watering or irritation (experienced the day before) recorded on a 4-point scale (0 to 3). During the 2 -week daily provocation period the symptom scores of nasal blockage, nasal discharge, sneezing, nasal itching, and the total symptom score experienced the day before increased significantly, demonstrating the priming effect.

no significant increase in symptom scores was found in the 30 minutes immediately after the provocation.

No correlations were found between numbers of eosinophils in biopsy sections or brush specimens on one hand and symptom scores on the other hand.

\section{Light and electron microscopic evaluation}

The material obtained by the brush technique consisted mainly of fully dispersed cells. Occasionally, small cell clumps were found. Cytocentrifuge preparations contained epithelial cells, mononuclear cells, granulocytes, and eosinophils.

The cryostat sections of the biopsy specimens of the nasal mucosa had an average surface area of 3 $\mathrm{mm}^{2}$. The epithelium could not be evaluated in four sections (once before provocation, once 6 days after first provocation, and twice 1 to 2 weeks after the last provocation). The lamina propria usually consisted of a looser subepithelial cell-rich layer with most of the mucous glands and a deeper collagenous cell-poor layer on the bone. The sections were all deep enough for assessment of both layers.

Morphologically, eosinophils could be easily identified by their dark violet nucleus and red cytoplasmic granules in both the cytocentrifuge preparations of brush specimens and cryostat sections of biopsy specimens in the Giemsa staining and by the red appearance in immunoalkaline phosphate staining (Fig. 2). With electron microscopy, eosinophils could be easily recognized in patients with allergy by the electron-dense cytoplasmic granules and the lobulated nucleus (Fig. 3).

\section{Number of eosinophils in brush specimens}

The percentages of eosinophils found per 500 cells in cytocentrifuge preparations increased significantly (time effect: $p<0.001$; see Methods section for explanation) with a maximum on day 9 (Fig. 4). The time course of the percentages of eosinophils obtained by the nasal brush method showed a considerable interindividual and day-byday intraindividual variation. The overall values ranged from $0 \%$ to $6 \%$ before provocation and reached a maximum of $46 \%$ in one specimen. In the control group the percentage of eosinophils was never higher than $1 \%$ (Fig. 4).

We wondered whether a correlation could be demonstrated between the numbers of eosinophils in the brush specimens and the biopsy sections. Rank correlation coefficients were determined between the number of eosinophils in the epithelium of biopsy sections and the average percentage of eosinophils in the brush specimens taken after a particular biopsy. No correlation could be determined in this way.

\section{Number of eosinophils in biopsy sections}

Epithelium. During the 2-week period of allergen challenge, the total number of eosinophils stained with BMK 13 and with Giemsa increased significantly in the epithelium (BMK 13, $p<0.001$; Giemsa, $p<0.001$ ) (Fig. 5). Also, a significant 

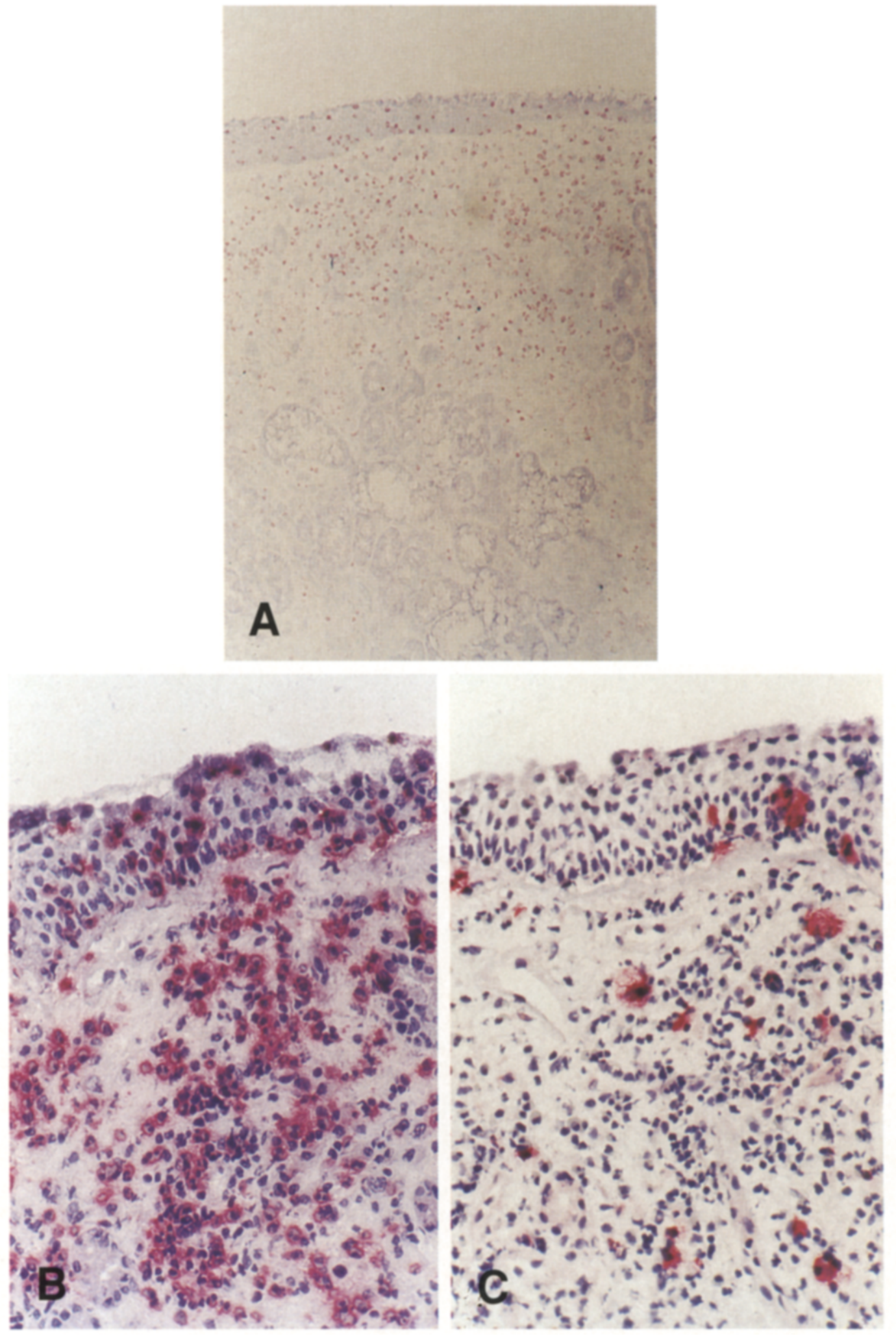

FIG. 2. Photomicrographs of three sections of one biopsy specimen of nasal mucosa of a patient with an isolated grass pollen allergy, taken at the end of the provocation period: stained with Giemsa (A), BMK 13 (B), and EG2 (C). In contrast to the biopsy specimen taken before provocation, large numbers of eosinophils (Giemsa and BMK 13) and to a lesser extent, activated eosinophils (EG2) were seen. Eosinophils were predominately found in the epithelium and subepithelial area (A). 


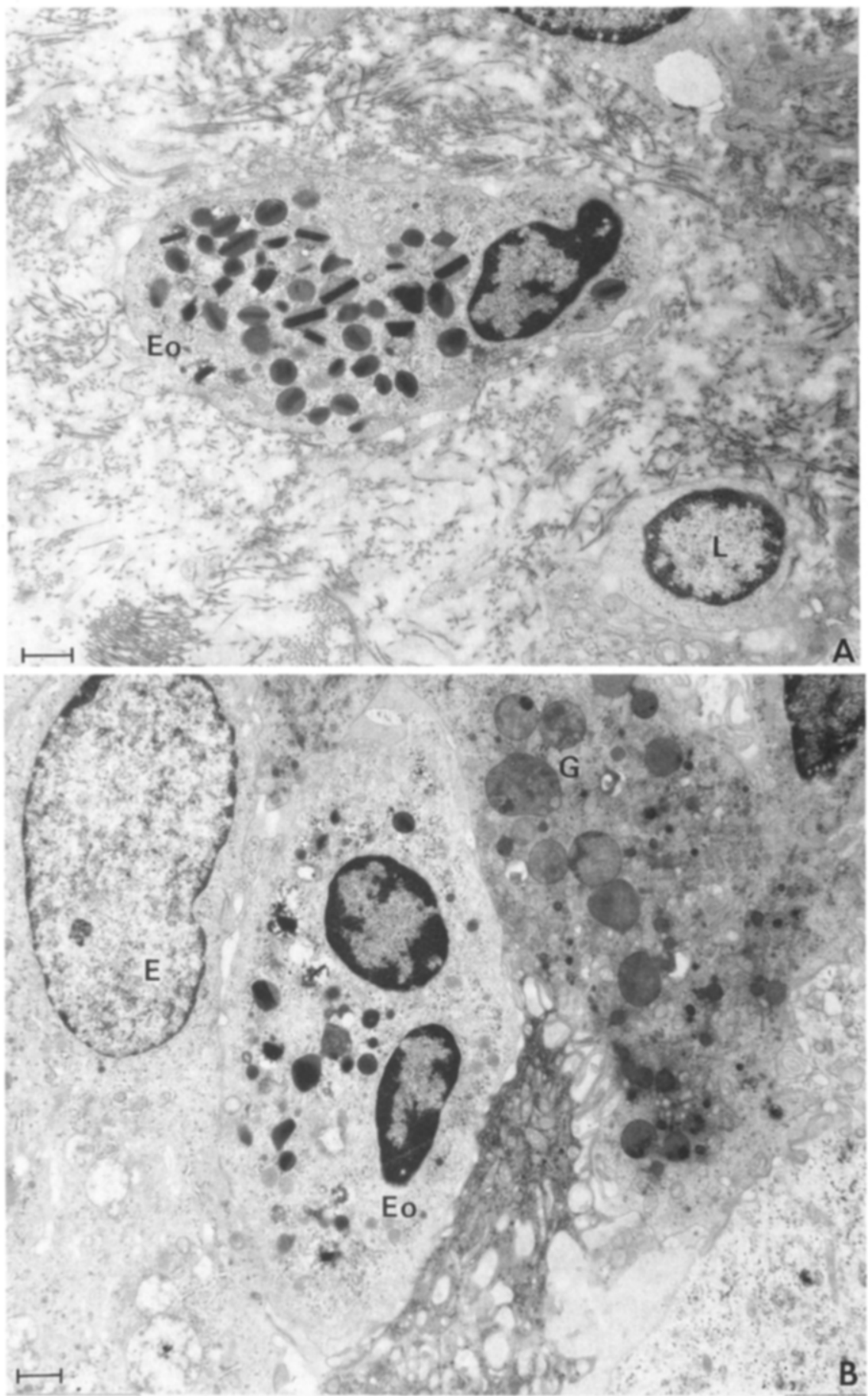

FIG. 3. Electron micrographs of two biopsy sections of the superficial layer of the nasal mucosa of a patient with an isolated grass pollen allergy. A, Before provocation the eosinophil is loaded with intact granules. B, During provocation the ultrastructure of the granules is altered, and the eosinophil is (partially) degranulated. Eo, Eosinophil; L, lymphocyte; $G$, goblet cell.

increase in the number of activated eosinophils stained with EG2 was found in the epithelium $(p<$ 0.001 ) (Fig. 5).

In the epithelium (Fig. 5) a couple of eosinophils were found only in a few sections stained with
BMK 13 before and $1 / 2$ hour after the first provocation. At 8 hours after the first provocation, eosinophils were found in almost every biopsy section of the epithelium until the end of the provocation period and even after the last provo- 


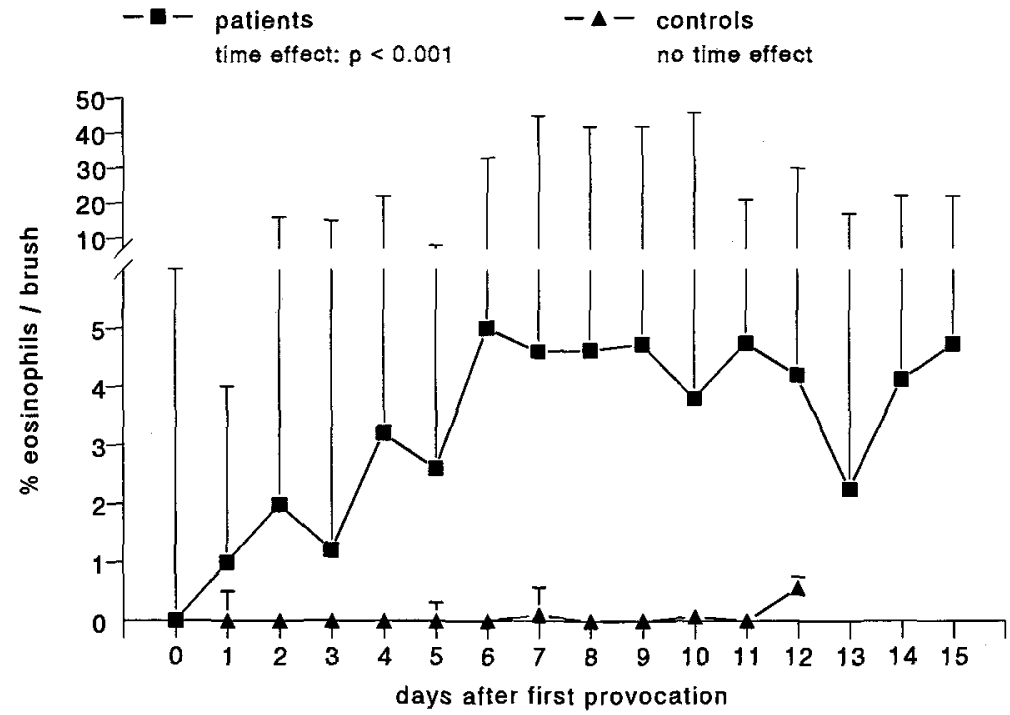

FIG. 4. Median percentage (lines) and ranges (bars) for Giemsa-stained eosinophils in the cytocentrifuge preparations of the nasal brush specimens from patients and control subjects. A significant increase was found during provocation (time effect: $p<0.001$ ), with a maximum on day 9.

cation. The significant increase in total number of eosinophils, and especially in the number of activated eosinophils in the epithelium, reached a maximum at the end of the provocation period (Fig. 5). Two weeks after the last provocation, no significant changes were found. At 8 hours after the first provocation, BMK $13^{+}$cells in the epithelium were not significantly increased in number as compared with the number before provocation.

Lamina propria. In the lamina propria, as in the epithelium, the total number of eosinophils stained with BMK 13 and with Giemsa increased significantly (BMK 13, $p<0.001$; Giemsa, $p<0.001$ ) (Fig. 5), and a significant increase in the number of activated eosinophils stained with EG2 was also found ( $p<0.001)$ (Fig. 5).

In the lamina propria very few eosinophils were spotted in the deep layers before provocation. Gradually, more eosinophils appeared in the lamina propria during the provocation period (Fig. 5). Perivascular infiltration around larger subepithelial blood vessels and attachment of eosinophils to the walls of these vessels occurred mainly after $1 / 2$ hour and 8 hours. According to the MannWhitney U rank-sum test, 8 hours after the first provocation, a significant increase $(p=0.03)$ in the number of BMK $13^{+}$cells was found in comparison with the number of BMK $13^{+}$cells before provocation. This is probably an indication of the late phase reaction. After 1 to 2 days, the eosinophils were seen more frequently in the subepithelial and deeper layers. The total number of eosinophils and the number of activated eosinophils increased significantly and was maximal at the end of the provocation period. Two weeks after the last provocation, no significant changes were found in total numbers of eosinophils and numbers of activated eosinophils in the lamina propria.

\section{Difference between BMK 13 and Giemsa staining}

The number of BMK $13^{+}$cells is higher than the number of Giemsa $^{+}$cells at almost every biopsy moment. This difference is significant in the epithelium $(p<0.001)$ and lamina propria $(p<$ $0.001)$ for counts from biopsy to biopsy $(n=56)$ according to the Wilcoxon matched-pairs signedrank test. When the same test was used for counts from patient to patient ( $n=17$, each $n$ is the average of four biopsy specimens taken per patient), the difference in epithelium just failed to reach significance $(p<0.06)$, and the difference in the lamina propria is significant again $(p<$ 0.02 ).

Rank correlation coefficients were computed for counts from biopsy to biopsy and from patient to patient. Significant correlations were found in both the epithelium $\left(r_{s}=0.68, p<0.001, n=47\right)$ and lamina propria $\left(r_{s}=0.75, p<0.001, n=53\right)$ in counts from biopsy to biopsy and only in the epithelium $\left(r_{s}=0.56, p<0.02, n=17\right)$. In the 
Epithelium
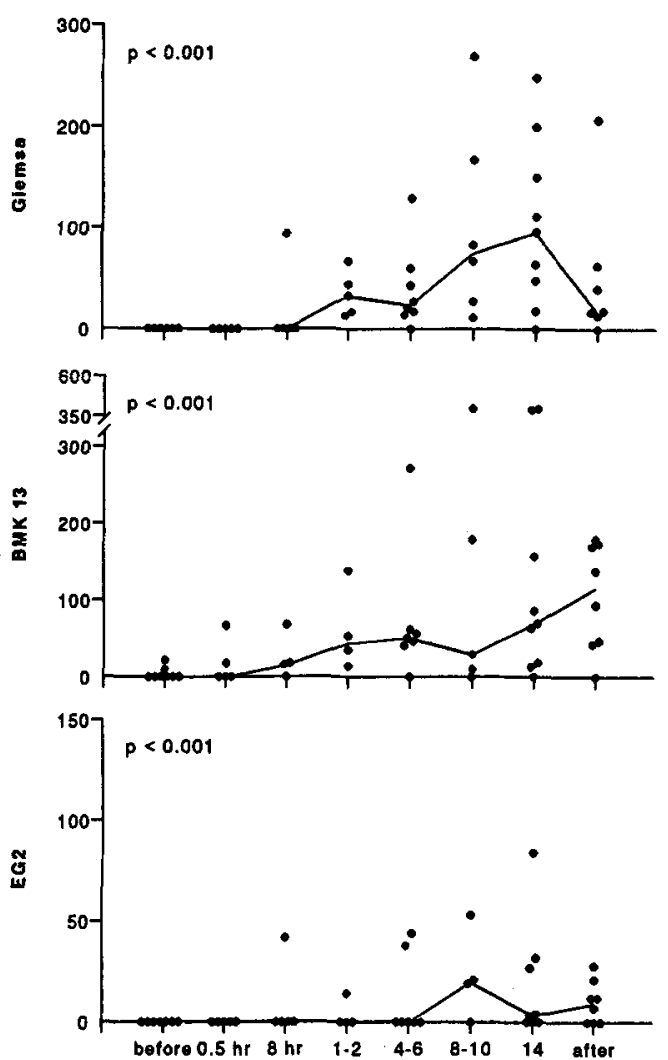

Lamina Propria
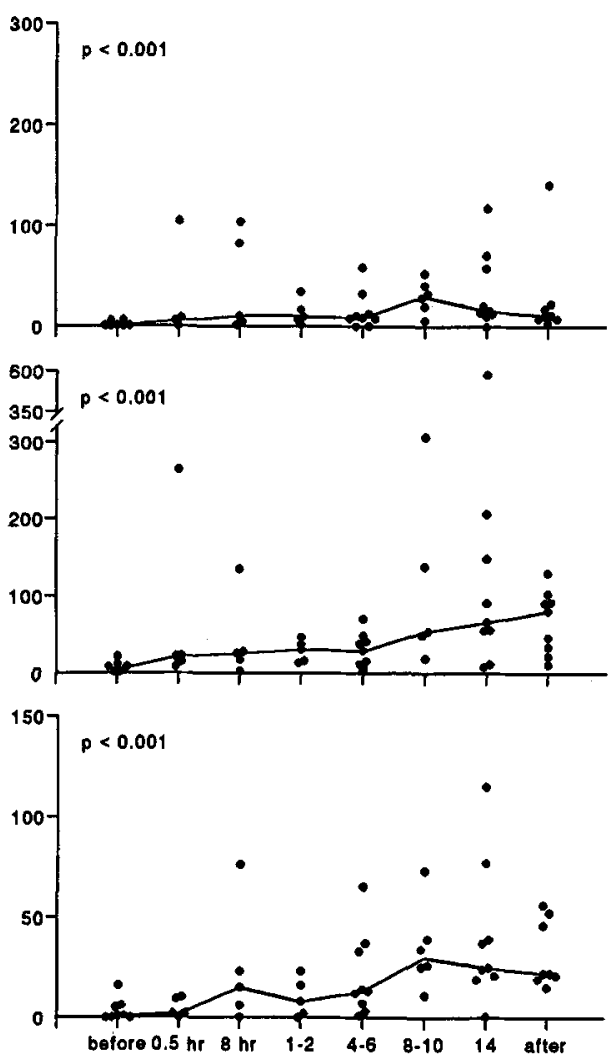

biopsy moment (hr/days)

FIG. 5. Giemsa, BMK 13, and EG2 staining of biopsy specimens taken before, at several moments during, and after a 2-week period of daily allergen challenge. Lines indicate median numbers. Given $p$ values indicate a significant time effect (an increase) during the provocation period for all stainings. See statistical analysis section for further explanation. Two weeks after the last provocation, no significant changes were found in comparison with the last biopsy specimen taken during provocation.

nonallergic control subjects no significant differences in cell numbers were found.

\section{Electron microscopy}

As determined by electron microscopy, after several days of allergen challenge, most eosinophils in the epithelium and subepithelial layer had fewer electron-dense cytoplasmic granules, and the granules showed signs of degranulation (Fig. 3). In the deeper layers most of the eosinophils had many electron-dense cytoplasmic granules.

\section{DISCUSSION}

The knowledge concerning the dynamics of the inflammatory cells in relation to the allergic stimulus and to the symptoms of allergic airway disease is poor. Studies performed until now were mainly focused on the acute ${ }^{5,10}$ and late phase reactions. ${ }^{6-8,24}$ Only a few studies have been concerned with activated eosinophils in various mucosal tissues. ${ }^{20}$ Different results have been obtained by various investigators, depending on the cell sampling technique used. Some investigators reported that eosinophils are numerous in nasal secretion and appear early in the allergic reaction. ${ }^{6-8,10}$ Others described an increased number of perivascular eosinophils and slightly dilated blood vessels in postchallenge biopsy specimens taken 30 minutes after provocation only. ${ }^{5}$ An increase in the number of eosinophils hours after allergen challenge has been found more often by using superficial cell sampling techniques, such as nasal lavages and brush sampling than by using the biopsy technique. 
In this study a combination of repeated biopsies and daily nasal brush sampling was used to obtain specimens of nasal mucosa. We investigated the dynamics and activation of eosinophils in the nasal mucosa and nasal secretions of patients with an isolated grass pollen allergy by using an artificial challenge model with well controlled study parameters. The combination of these two cell sampling methods provided maximum information about eosinophil dynamics in the nasal mucosa.

To detect eosinophils we used Giemsa staining and the monoclonal antibody BMK 13 directed to major basic protein. We realize that basophils also contain major basic protein, ${ }^{25}$ but we did not find large numbers of basophils in the nasal mucosa. Therefore we concluded that BMK 13 antibody is a more sensitive paneosinophil marker than Giemsa staining, because we found significantly higher numbers of BMK $13^{+}$cells in the biopsy sections of Giemsa $^{+}$cells.

In the brush specimens we found a rapid increase of eosinophils $1 / 2$ hour and 8 hours after the first provocation. This rapid increase is in accordance with results of other studies. ${ }^{6,7,10}$ In the biopsy specimens, however, no eosinophils were found in the epithelium $1 / 2$ hour and 8 hours after the first provocation. Only a slight infiltration of perivascular eosinophils around large subepithelial blood vessels and few eosinophils attached to the wall of the vessel were seen in the first period. This was also found by other investigators. ${ }^{5}$ Adhesion molecules are probably involved. An increase of adhesion molecules was found by other investigators. ${ }^{26}$ An explanation for differences in the number of eosinophils between brush and biopsy specimens at these early time points is a rapid migration of eosinophils from the subepithelial blood vessels over a rather short distance through the nasal mucosa to the surface of the epithelium. Another explanation is an increased de-adhesion and recoverability of cells at the surface, making them more accessible to the brushing technique.

Furthermore, this study demonstrates that in both nasal biopsy and nasal brush specimens the number of eosinophils continued to increase not only immediately after the first provocation, but during the entire provocation period. In the lamina propria, and especially in the epithelium of the nasal mucosa, the increase in eosinophils continued until the last day of the provocation period. This prolonged increase in the number of eosinophils is in accordance with the results of other studies performed during natural allergen exposure in the grass pollen season ${ }^{4}$ and during pro- longed artificial allergen challenge. ${ }^{8}$ Because these authors focused on the acute and late phase reactions, the provocation period was much shorter. In this study the increase seemed to be more extreme in the epithelium than in the lamina propria. This difference can be ascribed to the higher overall cell density in the epithelium than in the lamina propria. Another explanation is that the allergic inflammatory response occurs in the superficial layers, such as the epithelium and subepithelial area. Eosinophils were often seen in these layers during provocation (Fig. 2), as were degranulated eosinophils (Fig. 3). In the brush specimens we found a significant increase in the number of eosinophils not only in the acute phase but also during the remainder of the provocation period with a maximum on day 9 . It is possible that the migration of eosinophils to the surface of the nasal mucosa reached its maximum at this time. Another explanation is that from day 9 on, the influx equaled the extent of degranulation of eosinophils. When studying the dynamics of eosinophils, the degranulated granulocytes, which are probably not stained, must also be taken into consideration. Therefore we evaluated the biopsy specimens of two patients with allergy by means of electron microscopy. We found degranulated eosinophils, such as mast cells, ${ }^{27}$ mainly in the epithelium and subepithelial layer. These eosinophils had few electron-dense cytoplasmic granules (Fig. 3). This indicates that the number of eosinophils in the superficial layers of the nasal mucosa of patients with allergy is probably underestimated in light microscopic evaluation of biopsy specimens stained with Giemsa solution and also, probably to a lesser extent, with BMK 13.

In the epithelium we found a significant increase of activated eosinophils; this increase occurred mainly during the second week. In the lamina propria the significant increase of activated eosinophils seemed to be caused by the increase in the second week as well.

These data indicate that not only changes in cell numbers in the acute and late phase reactions are of importance in the pathophysiology of the allergic reaction, but also the changes that occur during prolonged allergen challenge and result in a chronic phase of the allergic reaction. Even 2 weeks after the first provocation, the total number of eosinophils and the number of activated eosinophils had not decreased significantly.

The considerable interindividual and day-by-day intraindividual variations in the percentage of eosinophils in the brush specimens indicate that the 
brush technique, like other superficial cell collecting techniques, is not suitable for clinical diagnostic purposes (e.g., to screen individual patients for allergic rhinitis). However, in studies as reported here, this repeated harvesting of mucosal cells by the brush technique is an excellent method for studying the allergic inflammatory reaction on the nasal mucosa surface for a prolonged period.

This study shows an increase in symptom scores of nasal blockage, nasal discharge, sneezing, nasal itching, and total symptom score experienced the day before. This indicates that the priming effect, described by others, ${ }^{28,29}$ also occurred in this study. No correlation was found between symptom scores and the total number of eosinophils and number of activated eosinophils in cryostat sections of nasal biopsy or nasal brush specimens. Some authors reported a correlation between number of eosinophils ${ }^{4,8}$ or mediators released by eosinophils ${ }^{7}$ and symptoms or pollen counts. Usually, no correlation was found. 6, 9, 30-32 This suggests that not only eosinophils, but also other cells in the nasal mucosa and their mediators, are responsible for the allergic symptoms and the priming effect.

\section{REFERENCES}

1. Fokkens WJ, Holm AF, Rijntjes E, Mulder PG, Vroom TM. Characterization and quantification of cellular infiltrates in nasal mucosa of patients with grass pollen allergy, non-allergic patients with nasal polyps and controls. Int Arch Allergy Appl Immunol 1990;93:66-72.

2. Bentley AM, Menz G, Storz C, et al. Identification of T lymphocytes, macrophages, and activated eosinophils in the bronchial mucosa in intrinsic asthma. Relationship to symptoms and bronchial responsiveness. Am Rev Respir Dis 1992;146:500-6.

3. Durham SR, Ying S, Varney VA, et al. Cytokine messenger RNA expression for IL-3, IL-4, IL-5, and granulocyte/ macrophage-colony-stimulating factor in the nasal mucosa after local allergen provocation: relationship to tissue eosinophilia. J Immunol 1992;148:2390-4.

4. Pipkorn U, Karlsson G, Enerback L. The cellular response of the human allergic mucosa to natural allergen exposure. J Allergy Clin Immunol 1988;82:1046-54.

5. Wihl JA, Mygind N. Studies on the allergen-challenged human nasal mucosa. Acta Otolaryngol 1977;84:281-6.

6. Bascom R, Pipkorn U, Lichtenstein LM, Naclerio RM. The influx of inflammatory cells into nasal washings during the late response to antigen challenge. Effect of systemic steroid pretreatment. Am Rev Respir Dis 1988;138:406-12.

7. Togias A, Naclerio RM, Proud D, et al. Studies on the allergic and nonallergic nasal inflammation. J ALLERGY Clin Immunol 1988;81:782-90.

8. Pipkorn U, Karlsson G, Enerback L. Nasal mucosal response to repeated challenges with pollen allergen. Am Rev Respir Dis 1989;140:729-36.

9. Borres MP, Irander K, Bjorksten B. Metachromatic cells in nasal mucosa after allergen challenge. Allergy 1990;45:98103.

10. Pelikan Z, Pelikan-Filipek M. Cytologic changes in the nasal secretions during the immediate nasal response [published erratum in J ALLERGY CLIN IMMUNol 1989;83:870]. J Allergy Clin Immunol 1988;82:1103-12.

11. Gleich GJ. The late phase of the immunoglobulin E-mediated reaction: a link between anaphylaxis and common allergic disease? J ALLERGY CLIN IMMUNOL 1982;70:160-9.

12. Greiff L, Pipkorn U, Alkner U, Persson CG. The 'nasal pool' device applies controlled concentrations of solutes on human nasal airway mucosa and samples its surface exudations/secretions. Clin Exp Allergy 1990;20:253-9.

13. Pipkorn U, Enerback L. A method for the preparation of imprints from the nasal mucosa. J Immunol Methods 1984;73:133-7.

14. Whelan CF. Problems in the examination of nasal smears in allergic rhinitis. J Laryngol Otol 1980;94:399-404.

15. Okuda $M$, Otsuka $H$. Basophilic cells in allergic nasal secretions. Arch Oto-Rhino-Laryngol 1977;214:283-9.

16. Pipkorn U, Karlsson G. Methods for obtaining specimens from the nasal mucosa for morphological and biochemical analysis. Eur Respir J 1988;1:856-62.

17. Fokkens WJ, Vroom TM, Rijntjes E, Mulder PG. Fluctuation of the number of CD-1(T6)-positive dendritic cells, presumably Langerhans cells, in the nasal mucosa of patients with an isolated grass-pollen allergy before, during, and after the grass-pollen season. J ALLERGY CLIN IMMUNOL 1989;84:39-43.

18. Fokkens WJ, Vroom TM, Gerritsma V, Rijntjes E. A biopsy method to obtain high quality specimens of nasal mucosa. Rhinology 1988;26:293-5.

19. Pipkorn U, Karlsson G, Enerback L. A brush method to harvest cells from the nasal mucosa for microscopic and biochemical analysis. J Immunol Methods 1988;112:3742.

20. Moqbel R, Barkans J, Bradley BL, Durham SR, Kay AB. Application of monoclonal antibodies against major basic protein (BMK-13) and eosinophil cationic protein (EG1 and EG2) for quantifying eosinophils in bronchial biopsies from atopic asthma. Clin Exp Allergy 1992;22: 265-73.

21. Feltkamp-Vroom T, Boode J. An embedding and sectioning technique for immunohistochemical studies of minute specimens of tissue. J Clin Pathol 1970;23:188-9.

22. Reynolds ES. The use of lead nitrate at high $\mathrm{pH}$ as an electron opaque stain in electron microscopy. J Cell Biol 1963;17:208-12.

23. Fokkens WJ, Vroom TM, Rijntjes E, Mulder PG. CD-1 (T6), HLA-DR-expressing cells, presumably Langerhans cells, in nasal mucosa. Allergy 1989;44:167-72.

24. Pelikan Z, Pelikan-Filipek M. Cytologic changes in the nasal secretions during the late nasal response. J ALLERGY Clin Immunol 1989;83:1068-79.

25. Golightly LM, Thomas LL, Dvorak AM, Ackerman SJ. Charcot-Leyden crystal protein in the degranulation and recovery of activated basophils. J Leukoc Biol 1992;51:38692.

26. Lee BJ, Naclerio RM, Bochner BS, et al. Nasal challenge with allergen upregulates the local expression of vascular endothelial adhesion molecules. J ALLERgY CLIN IMMUNOL 1994;94:1006-16.

27. Fokkens WJ, Godthelp T, Holm AF, et al. Dynamics of mast cells in the nasal mucosa of patients with allergic 
rhinitis and non-allergic controls: a biopsy study. Clin Exp Allergy 1992;22:701-10.

28. Connell JT. Quantitative intranasal pollen challenge. II. Effect of daily pollen challenge, environmental pollen exposure, and placebo challenge on the nasal membrane. $\mathbf{J}$ Allergy 1968;41:123-9.

29. Wachs M, Proud D, Lichtenstein LM, et al. Observations on the pathogenesis of nasal priming. J ALIERGY CLIN IMMUNOL 1989;84:492-501.

30. Andersson M, Andersson P, Venge P, Pipkorn U. Eosinophils and eosinophil cationic protein in nasal lavages in allergen-induced hyperresponsiveness: effects of topical glucocorticosteroid treatment. Allergy 1989;44:342-8.

31. Klementsson $\mathrm{H}$, Andersson $\mathrm{M}$, Baumgarten $\mathrm{CR}$, Venge $\mathbf{P}$, Pipkorn U. Changes in non-specific nasal reactivity and eosinophil influx and activation after allergen challenge. Clin Exp Allergy 1990;20:539-47.

32. Klementsson $H$, Andersson M, Pipkorn U. Allergeninduced increase in nonspecific nasal reactivity is blocked by antihistamines without a clear-cut relationship to eosinophil influx. J Allergy Clin Immunol 1990;86: 466-72. 